Pesq. Vet. Bras. 36(Supl.1):95-100, junho 2016 DOI: 10.1590/S0100-736X2016001300014

\title{
Perfil eletroforético do colostro de ovelhas suplementadas com propileno glicol e cobalto associado à vitamina $B_{12}$ no final da gestação ${ }^{1}$
}

\author{
Anne Grace S.S. Campos ${ }^{2 *}$, Rogério A. dos Santos², José Augusto B. Afonso ${ }^{3}$, Pierre \\ C. Soares ${ }^{4}$, José J. Fagliari ${ }^{5}$, Paulo C. Silva ${ }^{5}$ e Carla L. de Mendonça ${ }^{3}$
}

\begin{abstract}
Campos A.G.S.S., Santos R.A., Afonso J.A.B., Soares P.C., Fagliari J.J., Silva P.C. \& Mendonça C.L. 2016. [Electrophoretic profile of the colostrum of ewes supplemented with propylene glycol and cobalt associated with vitamin $B_{12}$ in late pregnancy.] Perfil eletroforético do colostro de ovelhas suplementadas com propileno glicol e cobalto associado à vitamina $\mathrm{B}_{12}$ no final da gestação. Pesquisa Veterinária Brasileira 36(Supl.1):95-100. Clínica de Bovinos, Campus Garanhuns, Universidade Federal Rural de Pernambuco, Avenida Bom Pastor s/n, Boa Vista, Cx. Postal 152, Garanhuns, PE 55292-270, Brazil. E-mail: annegracevet@yahoo.com.br
\end{abstract}

This study aimed to evaluate the proteinogram of the colostrum of ewes submitted to administration of propylene glycol and cobalt associated with vitamin $\mathrm{B}_{12}$ in late pregnancy. Eighteen pregnant Santa Inês ewes 18 months to 5 years old were distributed by probabilistic sampling into three experimental groups, about 30 days before the expected delivery date. In group $1(\mathrm{G} 1 / \mathrm{n}=6)$, daily oral doses of $30 \mathrm{ml}$ propylene glycol PA were administered; Group $2(\mathrm{G} 2 / \mathrm{n}=2)$ received a daily oral dosage of $1 \mathrm{mg}$ cobalt chloride in $1 \%$ solution and $2 \mathrm{mg}$ of vitamin $B_{12}$ intramuscularly once a week, and Group $3(\mathrm{G} 3 / \mathrm{n}=6)$ was the control group. Soon after delivery $30 \mathrm{~mL}$ of colostrum was harvested from each ewe, which were stored in appropriate containers and sent to the laboratory. After homogenization, we added to each $1000 \mu \mathrm{L}$ of colostrum $75 \mu \mathrm{L}$ solution of rennin, which was kept in a water bath at $37^{\circ} \mathrm{C}$ for about 20 minutes and centrifuged at $21.000 \mathrm{G}$ for 10 minutes in a refrigerated centrifuge. Later, the intermediate fraction, corresponding to colostrum whey, was aliquoted and kept in a $-80^{\circ} \mathrm{C} \mathrm{ul-}$ trafreezer for subsequent determination of proteins. The determination of the total colostral protein whey was performed using a commercial reagent, observing the linearity test for colostrum. The separation of proteins was performed using the technique of electrophoresis on polyacrylamide gel containing sodium dodecyl sulfate (SDS-PAGE). Lactoferrin, IgA, albumin, IgG heavy chain (IgGCP), $\beta$-casein, IgG light chain (IgGCL), $\beta$-lactoglobulin and $\alpha$-lactalbumin proteins were identified. There was no influence of the administration of supplements during late pregnancy on the concentration of proteins identified in the colostrum of the ewes.

INDEX TERMS: Colostrum, SDS-PAGE, whey proteins, gluconeogenic supplements, peripartum, sheep.

\footnotetext{
${ }^{1}$ Recebido em 12 de maio de 2015.

Aceito para publicação em 13 de abril de 2016.

${ }^{2}$ Programa de Pós-Graduação em Ciência Veterinária, Universidade Federal Rural de Pernambuco (UFRPE), Av. Dom Manuel de Medeiros s/n, Dois Irmãos, Recife, PE 52171-030, Brasil. *Autor para correspondência: annegracevet@yahoo.com.br

${ }^{3}$ Clínica de Bovinos, Campus Garanhuns, UFRPE, Av. Bom Pastor s/n, Boa Vista, Cx. Postal 152, Garanhuns, PE 55292-570, Brasil.

${ }^{4}$ Departamento de Medicina Veterinária, UFRPE, Av. Dom Manuel de Medeiros s/n, Dois Irmãos, Recife, PE 52171-030, Brasil.

${ }^{5}$ Faculdade de Ciências Agrárias e Veterinárias, Universidade Estadual Paulista Júlio de Mesquita Filho (Unesp), Campus de Jaboticabal, Via de acesso Prof. Paulo Donato Castellane s/n, Jaboticabal, SP 14884-900, Brasil.
}

RESUMO.- Este trabalho teve por objetivo avaliar o proteinograma do colostro de ovelhas submetidas a administração de propileno glicol e de cobalto associado à vitamina $\mathrm{B}_{12}$ no final da gestação. Dezoito ovelhas da raça Santa Inês, prenhas e com idade variando entre 18 meses a cinco anos foram distribuídas, por amostragem probabilística em três grupos experimentais, aproximadamente 30 dias antes da data prevista para o parto. No Grupo $1(\mathrm{G} 1 / \mathrm{n}=6)$ foram administrados $30 \mathrm{~mL}$ de propileno glicol P.A. via oral diariamente; no Grupo $2(\mathrm{G} 2 / \mathrm{n}=6)$ foi administrado $1 \mathrm{mg}$ de cloreto de cobalto em solução a $1 \%$ via oral diariamente e $2 \mathrm{mg}$ de vitamina $\mathrm{B}_{12}$, via intramuscular semanalmente 
e no Grupo 3 (G3/n=6): grupo controle. Logo após o parto procedeu-se a colheita de $30 \mathrm{~mL}$ de colostro, que foram acondicionados em recipientes apropriados e encaminhados ao laboratório. Após homogeneização, adicionou-se a cada $1.000 \mu \mathrm{L}$ de colostro, $75 \mu \mathrm{L}$ de solução de renina, que foi mantido em banho-maria a $37^{\circ} \mathrm{C}$ por aproximadamente 20 minutos e centrifugado a $21.000 \mathrm{G}$ durante dez minutos em centrífuga refrigerada. Posteriormente, a fração intermediária, correspondente ao soro do colostro, foi aliquotada e mantida em ultrafreezer a $-80^{\circ} \mathrm{C}$ para posterior determinação das proteínas. A determinação da proteína total do soro colostral foi realizada empregando-se reagente comercial. A separação das proteínas foi realizada utilizando-se a técnica de eletroforese em gel de poliacrilamida contendo dodecil sulfato de sódio (SDS-PAGE). Foram identificadas as proteínas IgA, lactoferrina, albumina, IgG de cadeia pesada (IgGCP), $\beta$-caseína, IgG de cadeia leve (IgG$\mathrm{CL}), \beta$-lactoglobulina and $\alpha$-lactoalbumina, não havendo influência da administração dos suplementos na fase final da gestação sobre as concentrações protéicas do colostro.

TERMOS DE INDEXAÇÃO: Colostro, eletroforese, proteínas do soro lácteo, suplementos gliconeogênicos, periparto, ovinos.

\section{INTRODUÇÃO}

A administração de suplementos gliconeogênicos em ruminantes durante o periparto é prática comum adotada na tentativa de minimizar o impacto econômico que os distúrbios metabólicos acarretam neste período. Dentre estes suplementos o propileno glicol vem sendo administrado como alternativa para minimizar o balanço energético negativo por sua ação na redução da concentração sanguínea de $\beta$-hidroxibutirato (BHB) e dos ácidos graxos não esterificados (AGNEs) e no aumento da concentração de glicose e insulina, a fim de melhorar a performance produtiva dos animais (Nielsen \& Ingvartsen 2004, Chiofalo et al. 2005, Santos et al. 2012). 0 cobalto vem sendo empregado na alimentação de fêmeas gestantes por ser importante microelemento utilizado pela microbiota do rúmen para a síntese de vitamina $\mathrm{B}_{12}$, que por sua vez é coenzima essencial no metabolismo do ácido propiônico, na gliconeogênese e na geração de energia. Ambos os suplementos são imprescindíveis para o desempenho produtivo do rebanho, interferindo no processo de mobilização das reservas energéticas e de gordura, neste período crítico para o animal, que precede o parto e o início da lactação (Duncan et al. 1981, Borges 2003, Afonso 2006).

O colostro é a primeira secreção láctea produzida, rico em imunoglobulinas, além de ser um alimento altamente energético, uma boa fonte de minerais, enzimas, hormônios, fatores de crescimento e peptídeos neuroendócrinos para o animal recém-nato (Kelly 2003, Nowak \& Poindron 2006, Bolzan et al. 2010). A composição do colostro é diferenciada do leite (Lemos et al. 2013), quando do estabelecimento da lactação, com algumas proteínas secretadas pela glândula mamária presentes em concentrações mais elevadas, conforme relatado com maior frequência nas espécies bovina e caprina (Levieux \& Ollier 1999, Levieux et al. 2002).
Na espécie ovina as informações qualitativas e quantitativas sobre as proteínas presentes no colostro são escassas na literatura nacional e internacional. Sendo a suplementação efetuada no final da gestação uma prática frequente na ovinocultura, este estudo teve por objetivo identificar e quantificar as proteínas presentes no soro colostral de ovelhas suplementadas com propileno glicol e com cobalto associado à vitamina $\mathrm{B}_{12}$ durante a fase final da gestação.

\section{MATERIAL E MÉTODOS}

Foram acompanhadas 18 ovelhas da raça Santa Inês prenhes, clinicamente sadias, pesando aproximadamente $40 \mathrm{~kg}$, mantidas em aprisco de experimentação. Aproximadamente 30 dias antes da data prevista para o parto, após avaliação ultrassonográfica, as ovelhas foram distribuídas por amostragem probabilística em três grupos e suplementadas, conforme a seguir: Grupo 1 (G1) $\mathrm{n}=6$ ) administrado $30 \mathrm{~mL}$ de propileno glicol P.A. (Propileno glicol P.A., Sigma Aldrich Brasil Ltda) via oral diariamente; Grupo 2 (G2) $\mathrm{n}=6$ ) administrado $1 \mathrm{mg}$ de cloreto de cobalto em solução a $1 \%$ via oral diariamente e $2 \mathrm{mg}$ de vitamina $\mathrm{B}_{12}$ (Monovin $\mathrm{B}_{12}$ Lab. Bravet Ltda) via intramuscular semanalmente (NRC 2007) e Grupo 3 $(\mathrm{G} 3 / \mathrm{n}=6)$ : grupo controle. Logo após o parto procedeu-se a avaliação clínica da glândula mamária (Diffay et al 2004) e a colheita de aproximadamente $30 \mathrm{~mL}$ de colostro, que foram acondicionados em recipientes apropriados e encaminhados ao laboratório sob refrigeração.

Para obtenção do soro empregou-se a técnica descrita por Lemos et al. (2013). Inicialmente procedeu-se a homogeneização da amostra e a cada $1.000 \mu \mathrm{L}$ de colostro acrescentou-se $75 \mu \mathrm{L}$ de solução de renina (coalho Estrela ${ }^{\circledR}$ ), que foi mantido em banho-maria a $37^{\circ} \mathrm{C}$ por aproximadamente 20 minutos e centrifugado a 21.000G durante dez minutos em centrífuga refrigerada (Mikro 200R). Posteriormente a fração intermediária, resultante da solução trifásica, correspondente ao soro do colostro, foi aliquotada em tubos tipo eppendorf e armazenadas em ultrafreezer ${ }^{2}$ a $-80^{\circ} \mathrm{C}$ para posterior caracterização das proteínas. A concentração da proteína total foi determinada empregando-se reagente comercial (Proteína total, Labtest Diagnóstica), observando-se a linearidade do teste. A separação das proteínas se deu pela técnica de eletroforese em gel de poliacrilamida contendo dodecil sulfato de sódio (SDS-PAGE), conforme descrito por Laemmli (1970) e Fagliari \& Silva (2002). Para a identificação das proteínas foi empregada como referência solução marcadora (Sigma Sigma- Aldrich Corporation, 3050 Spruce Street, St Louis, MO 63103, USA.) com diferentes pesos moleculares (6.500-200.000 Da) e as proteínas purificadas lactoferrina, $\beta$-lactoglobulina e a $\alpha$-lactoalbumina. A determinação das concentrações protéicas foi obtida por meio de densitômetro computadorizado (Shimatzu CS 9301). Em função do protocolo empregado (SDS-PAGE), a imunoglobulina G (IgG) foi separada em duas cadeias, cadeia leve (IgGCL) e cadeia pesada (IgGCP).

Os resultados foram organizados com dados de medidas de tendência central e submetidos à análise de variância para avaliação de efeito de grupo (G1, G2 e G3). Os valores médios foram comparados pelo teste de Student-Newman-Keuls adotando-se nível de $5 \%$ de probabilidade. Realizou-se a análise de correlação de Pearson entre pares de variáveis do proteinograma (Little \& Hill 1978). Para análise dos dados, empregou-se o programa computacional Statistical Analysis System (SAS 2009). 0 trabalho obteve parecer favorável da Comissão de Ética no Uso de Animais (CEUA)/UFRPE de acordo com a resolução 269/2007 do CEPE/ UFRPE. 


\section{RESULTADOS E DISCUSSÃO}

No eletroforetograma foram identificadas 23 proteínas com pesos moleculares variando de $11.000 \mathrm{Da}$ a 215.000 Da presentes no colostro. Destas, oito proteínas (imunoglobulina A-IgA, imunoglobulina G - IgG de cadeia pesada (IgGCP), IgG de cadeia leve (IgGCL), lactoferrina, albumina, $\beta$-lactoglobulina, $\alpha$-lactoalbumina e $\beta$-caseína) foram consideradas de interesse e submetidas à análise estatística.

As proteínas identificadas no colostro das ovelhas foram também verificadas por Rocha (2010) analisando o colostro de vacas da raça Canchim. Muitas destas proteínas também foram relatadas no leite de ovelhas obtido em diferentes fases da lactação, conforme relatado por Lemos et al. (2013), no entanto, as concentrações proteicas durante toda a lactação, foram distintas, sendo a magnitude da concentração protéica muito mais expressiva no colostro, quando comparado ao leite, destacando-se as concentrações das imunoglobulinas (IgA e IgG), da lactoferrina, da $\beta$-lactoglobulina e da $\alpha$-lactoalbumina.

Ao avaliar a influência da suplementação realizada durante a fase final da gestação sobre a concentração das proteínas presentes no colostro, verificou-se não haver diferença significativa entre os três grupos estudados $(\mathrm{P}>0,05)$, sendo desta forma, discutido os valores médios de cada uma das variáveis, conforme pode ser visualizado no Quadro 1.

Quadro 1. Medidas de tendência central das concentrações das proteínas identificadas no colostro de ovelhas suplementadas com propileno glicol, cobalto associado à vitamina B12 e o grupo controle no final da gestação

\begin{tabular}{|c|c|c|c|c|c|c|}
\hline \multirow[t]{2}{*}{ Proteínas colostro } & & \multicolumn{5}{|c|}{ Grupos experimentais } \\
\hline & & Controle & Co + Vit. B12 & Propileno glicol & Média Geral & $\mathrm{P}$ \\
\hline \multirow{5}{*}{ Proteína Total (g/dL) } & $\mathrm{x}$ & $19,33^{\mathrm{a}}$ & $15,33^{\mathrm{a}}$ & $17,27^{\mathrm{a}}$ & & \\
\hline & s & 5,75 & 6,77 & 4,12 & & \\
\hline & $\mathrm{Md}$ & 19,32 & 16,49 & 18,12 & 17,31 & 0,6191 \\
\hline & Sup. & 25,08 & 23,46 & 21,00 & & \\
\hline & Inf. & 13,58 & 3,62 & 10,56 & & \\
\hline \multirow[t]{5}{*}{ Lactoferrina (mg/dL) } & $\mathrm{x}$ & $700,37^{a}$ & $685,08^{a}$ & $458,96^{a}$ & & \\
\hline & $\mathrm{s}$ & 274,39 & 535,80 & 218,94 & & \\
\hline & Md & 601,90 & 713,90 & 583,30 & 614,80 & 0,6012 \\
\hline & Sup. & 1010,40 & 1255,90 & 663,60 & & \\
\hline & Inf. & 488,80 & 99,50 & 214,30 & & \\
\hline \multirow[t]{5}{*}{ Albumina (mg/dL) } & $\mathrm{x}$ & $1273,53^{a}$ & $745,43^{a}$ & $676,62^{a}$ & & \\
\hline & $\mathrm{s}$ & 791,70 & 504,36 & 304,41 & & \\
\hline & $\mathrm{Md}$ & 908,50 & 749,00 & 689,50 & 898,53 & 0,2816 \\
\hline & Sup. & 2181,90 & 1351,20 & 1000,20 & & \\
\hline & Inf. & 730,20 & 181,00 & 352,80 & & \\
\hline \multirow[t]{5}{*}{$\operatorname{IgA}(\mathrm{mg} / \mathrm{dL})$} & $\mathrm{x}$ & $27,03^{\mathrm{a}}$ & $23,33^{\mathrm{a}}$ & $20,73^{\mathrm{a}}$ & & \\
\hline & $\mathrm{s}$ & 8,21 & 9,14 & 7,60 & & \\
\hline & $\mathrm{Md}$ & 30,90 & 23,65 & 23,10 & 23,70 & 0,6059 \\
\hline & Sup. & 32,60 & 35,10 & 28,90 & & \\
\hline & Inf. & 17,60 & 9,05 & 8,40 & & \\
\hline \multirow{5}{*}{$\operatorname{IgGCL}(\mathrm{mg} / \mathrm{dL})$} & $\mathrm{x}$ & $4362,43^{a}$ & $3534,98^{a}$ & $4022,08^{\mathrm{a}}$ & & \\
\hline & $\mathrm{s}$ & 1453,83 & 2131,54 & 1088,51 & & \\
\hline & $\mathrm{Md}$ & 4192,40 & 3665,05 & 3913,90 & 3973,16 & 0,7737 \\
\hline & Sup. & 5893,80 & 6733,00 & 5523,00 & & \\
\hline & Inf. & 3001,10 & 459,70 & 2766,70 & & \\
\hline \multirow[t]{5}{*}{$\operatorname{IgGCP}(\mathrm{mg} / \mathrm{dL})$} & $\mathrm{x}$ & $4903,23^{a}$ & $3726,0^{a}$ & $3923,34^{a}$ & & \\
\hline & s & 1003,39 & 1003,39 & 1198,85 & & \\
\hline & $\mathrm{Md}$ & 5100,40 & 5100,40 & 4408,80 & 4576,6 & 0,6453 \\
\hline & Sup. & 5793,40 & 5793,40 & 5309,10 & & \\
\hline & Inf. & 3815,90 & 3815,90 & 2625,00 & & \\
\hline \multirow[t]{5}{*}{$\beta$-caseína (mg/dL) } & $\mathrm{x}$ & $82,77^{\mathrm{a}}$ & $155,22^{\mathrm{a}}$ & $80,80^{\mathrm{a}}$ & & \\
\hline & $\mathrm{s}$ & 44,12 & 131,47 & 73,10 & & \\
\hline & $\mathrm{Md}$ & 71,90 & 135,90 & 58,10 & 106,26 & 0,4282 \\
\hline & Sup. & 131,30 & 312,60 & 210,00 & & \\
\hline & Inf. & 45,10 & 13,00 & 32,60 & & \\
\hline \multirow[t]{5}{*}{$\beta$-lactoglobulina (mg/dL) } & $x$ & $6864,13^{a}$ & $4353,18^{a}$ & $5499,16^{a}$ & & \\
\hline & $\mathrm{s}$ & 2439,64 & 1591,41 & 1296,63 & & \\
\hline & $\mathrm{Md}$ & 6704,00 & 4542,55 & 6090,00 & 5572,16 & 0,1495 \\
\hline & Sup. & 9379,90 & 6169,90 & 6733,40 & & \\
\hline & Inf. & 4508,50 & 1513,10 & 3442,50 & & \\
\hline \multirow[t]{5}{*}{$\alpha$-lactoalbumina (mg/dL) } & $\mathrm{x}$ & $912,47^{\mathrm{a}}$ & $771,85^{a}$ & $1342,12^{\mathrm{a}}$ & & \\
\hline & $\mathrm{s}$ & 233,02 & 339,84 & 1025,64 & & \\
\hline & $\mathrm{Md}$ & 940,50 & 677,70 & 630,50 & 1008,81 & 0,3877 \\
\hline & Sup. & 1130,20 & 1430,10 & 2646,00 & & \\
\hline & Inf. & 666,70 & 448,80 & 543,40 & & \\
\hline
\end{tabular}

Letras iguais na mesma linha não diferem ao nível de $5 \%$ de probabilidade. $\mathrm{x}=$ Média, $\mathrm{s}=$ Desviopadrão, Md = Mediana, Sup. $=$ Limite superior, Inf. $=$ Limite inferior. 
Proteína total. Os valores médios da proteína total presente no colostro dos três grupos estudados foi de 17,31g/dL (Quadro 1), concentrações estas superiores às relatadas na espécie caprina por Rudovsky et al. (2008). As concentrações elevadas da proteína total no colostro são justificadas pela passagem, principalmente, de imunoglobulinas, particularmente IgG da corrente circulatória para a glândula mamária, podendo ser ratificado pela alta correlação positiva entre as concentrações da proteína total e as imunoglobulinas IgA $(r=0,86, P<0,0001)$, IgGCL $(r=0,85$; $\mathrm{P}<0,0001)$ e a IgGCP $(\mathrm{r}=0,74, \mathrm{P}<0,0026)$ (Quadro 2$)$.

Em vacas leiteiras, suplementadas antes e após o parto com cobalto e vitamina $\mathrm{B}_{12}$, submetidas a cinco tratamentos distintos, não foi observado efeito de grupo, semelhante a este estudo, no entanto a concentração proteica no colostro foi superior na vaca $(23,54 \mathrm{~g} / \mathrm{dL}$ ) (Akins et al. 2013), quando comparado à ovelha $(17,31 \mathrm{~g} / \mathrm{dL})$, provavelmente pelo emprego de metodologias distintas.

Imunoglobulinas. 0 proteinograma permitiu verificar concentrações médias de $23,70 \mathrm{mg} / \mathrm{dL}, 3973,16 \mathrm{mg} / \mathrm{dL}$ e $4576,6 \mathrm{mg} / \mathrm{dL}$ para as imunoglobulinas IgA, IgG (IgGCL) e IgG (IgGCP), respectivamente (Quadro 1), ratificando a importância vital da IgG para os ruminantes recém natos (Indyk \& Filonzi 2003, Tizard 2013), sendo a IgG a proteína identificada em maior concentração no colostro das ovelhas. A concentração das imunoglobulinas presentes no colostro representou aproximadamente metade da concentração da proteína total, divergindo da espécie caprina, na qual foi relatada concentração de Igs representando um terço da concentração total da proteína presente no colostro (Rudovsky et al. 2008). A concentração elevada das Igs no colostro é resultante da transudação do plasma sanguíneo para o interior da glândula mamária, a fim de fornecer proteção necessária para os borregos. A IgG desempenha papel fundamental nos mecanismos de defesa dependentes de anticorpos, quando comparado à outras classes de imunoglobulinas, participando na defesa dos espaços teciduais e das superfícies corpóreas (Moretti et al. 2010). A IgA presente no colostro é resultante, cerca de cinquenta por cento, da circulação sanguínea, sendo de grande importância sua presença nos fluidos corpóreos, particularmente do trato gastrointestinal e respiratório atuando na defesa do recém nato frente aos agentes infecciosos, comuns nas primeiras semanas de vida (Tizard 2013).

Entre as imunoglobulinas, verificou-se alta correlação positiva entre a IgGCP e a IgGCL $(\mathrm{r}=0,74 ; \mathrm{P}<0,0022)$; a IgGCP e a IgA $(r=80 ; P<0,0006) ;$ a IgGCL e a IgA $(r=0,79$; $\mathrm{P}<0$,0007) (Quadro 2).

A suplementação com cobalto três semanas antes do parto, conforme relatos de Boland et al. (2008), não influenciou a concentração de IgG presente no colostro de ovelhas, sendo verificado concentração média de $8600 \mathrm{mg} / \mathrm{dL}$ desta classe de imunoglobulina, resultados estes semelhantes aos deste estudo. Em vacas os resultados foram divergentes, Akins et al. (2013) constataram que a suplementação com cobalto e vitamina $\mathrm{B}_{12}$, não alteraram as concentrações de IgG e IgM de vacas, entretanto no trabalho de Kincaid \& Socha (2007) a suplementação com cobalto aumentou a IgG do colostro de $3.725 \mathrm{mg} / \mathrm{dL}$ para $5.655 \mathrm{mg} / \mathrm{dL}$.

Lactoferrina. 0 valor médio da lactoferrina no colostro das ovelhas verificado entre os grupos $(P>0,05)$ foi de 614,80mg/dL, (Quadro 1), concentração esta superior a observada por Baroza (2007) no colostro de cabras e muito superior a verificada na secreção láctea de ovelhas (Lemos et al.2013), o que é esperado, quando comparado ao leite, tendo em vista a grande importância desta glicoproteína presente em altas concentrações no colostro para o neonato, uma vez que faz parte da defesa natural, protegendo tanto a glândula mamária quanto o neonato contra infecções virais e bacterianas (Robblee et al. 2003, Yekta et al. 2011). A lactoferrina é a principal substância láctea que possui a capacidade de ligação com o ferro livre, e este por sua vez, é um dos elementos essenciais para o crescimento bacteriano. Atua como quelante do ferro, impedindo que as bactérias utilizem este mineral, crucial para o seu metabolismo. Outra função importante desta proteína é que por se conjugarem a receptores existentes nas vilosidades intestinais, impedem a multiplicação de bactérias como a Escherichia coli (Weinberg 1978, Brock 1980, Yekta et al. 2011).

Albumina. 0 valor médio da concentração da albumina no colostro foi de $898,53 \mathrm{mg} / \mathrm{dL}$, valores estes inferiores

Quadro 2. Matriz de correlação de Pearson (r) e nível de significância (p) entre pares das proteínas identificadas no colostro de ovelhas suplementadas com propileno glicol e cobalto associado à vitamina $B 12$

\begin{tabular}{|c|c|c|c|c|c|c|c|c|c|}
\hline & Proteína Total & Lactoferrina & Albumina & $\operatorname{Ig} \mathrm{A}$ & IgGCL & IgGCP & $\beta$-caseina & $\beta$-lactoglobulina & $\alpha$-lactoalbumina \\
\hline \multirow[t]{2}{*}{ Proteína Total } & 1 & 0,60 & 0,60 & 0,86 & 0,85 & 0,74 & 0,24 & 0,92 & 0,40 \\
\hline & & 0,0252 & 0,0268 & 0,0001 & 0,0001 & 0,0026 & 0,4165 & 0,0001 & 0,1616 \\
\hline Lactoferrina & & 1 & 0,48 & 0,70 & 0,42 & 0,52 & 0,40 & 0,35 & $-0,13$ \\
\hline \multirow[t]{2}{*}{ Albumina } & & & 1 & 0,56 & 0,48 & 0,61 & $-0,17$ & 0,61 & $-0,36$ \\
\hline & & & & 0,0384 & 0,0841 & 0,0209 & 0,5592 & 0,0220 & 0,2109 \\
\hline $\operatorname{IgA}$ & & & & 1 & 0,79 & 0,80 & 0,25 & 0,78 & 0,09 \\
\hline IgGCL & & & & & & 0,0022 & 0,7162 & 0,0013 & 0,3199 \\
\hline \multirow[t]{2}{*}{ IgGCP } & & & & & & 1 & $-0,25$ & 0,0043 & 0,3199 \\
\hline & & & & & & & 0,3969 & 0,71 & $-0,12$ \\
\hline \multirow[t]{2}{*}{$\beta$-caseina } & & & & & & & 1 & 0,02 & 0,34 \\
\hline & & & & & & & & 0,9603 & 0,2419 \\
\hline \multirow[t]{2}{*}{$\beta$-lactoglobulina } & & & & & & & & 1 & 0,38 \\
\hline & & & & & & & & & 0,1749 \\
\hline
\end{tabular}


aos observados por Baroza (2007), contudo superiores aos verificados por Levieux et al. (2002), ambos em colostro de cabras. No colostro de vacas, estes valores são ainda mais baixos quando comparados aos animais da espécie caprina, conforme verificados por Levieux \& Ollier (1999) e Sant'ana (2004). Os valores observados de albumina podem ser explicados pela permeabilidade capilar aumentada no úbere próximo ao parto, uma vez que esta proteína participa no transporte de ácidos graxos, bilirrubina, algumas drogas, além de cátions e minerais como, cálcio, cobre e zinco, resultando na passagem aumentada dos componentes sanguíneos para a glândula mamária (Östensson 1993, Eckersall 2008).

$\boldsymbol{\beta}$-caseína. 0 valor médio da $\beta$-caseína entre os grupos foi de $106,26 \mathrm{mg} / \mathrm{Dl}$. Valores elevados verificados no colostro são decorrentes do seu armazenamento na glândula mamária durante o período seco (Larson \& Kendall 1957), tendo em vista o seu papel no fornecimento do suprimento protéico ao recém-nascido, como também precursores de peptídeos bioativos (Korhonen \& Pihlanto 2007), que estimulam a atividade fagocítica dos macrófagos e devem ser capazes de atuar na proliferação e maturação de células $\mathrm{T}$ e células natural killer para a defesa do neonato contra ampla variedade de bactérias, particularmente as entéricas (Migliore-Samour \& Jollés 1988, Lahov \& Regelson 1996). Peptídeos derivados da caseína vêm merecendo atenção como possível fonte de bioativo natural proporcionando benefícios para saúde humana (Hernández-Castellano et al. 2014). As concentrações de $\beta$-caseína verificadas no colostro das ovelhas foram inferiores aos descritos na vaca durante a fase média e final da lactação, conforme observado por Sant'ana (2004).

$\boldsymbol{\beta}$-lactoglobulina. Observou-se no colostro de ovelhas valor médio de $\beta$-lactoglobulina de $5.572,16 \mathrm{mg} / \mathrm{dL}$, concentração esta superior ao relatado por Levieux \& Ollier (1999), Levieux et al. (2002) e Baroza (2007) em colostro de vacas e cabras. Perez et al. (1990), trabalhando com colostro de ovelhas, observaram concentração de $1.730 \mathrm{mg} / \mathrm{dL}$, diminuindo acentuadamente nas primeiras $24 \mathrm{~h}$ após o parto e de forma mais gradativa, nas duas primeiras semanas de lactação, chegando a atingir $20 \%$ do valor inicial. Valores elevados da $\beta$-lactoglobulina são frequentemente verificados na primeira e última fases da lactação, conforme relatado por Levieux \& Ollier (1999), Levieux et al. (2002) e Lemos et al. (2013). A diferença da concentração desta variável observada neste estudo, quando comparada a concentração relatada por Perez et al. (1990) pode estar relacionada a metodologia empregada, em que as proteínas foram mensuradas pela imunoeletroforese quantitativa. Apesar das funções desta proteína não serem totalmente conhecidas, tem sido sugerido possuir a capacidade de inibição da aderência bacteriana tanto para as proteínas intestinais como para o epitélio gastrointestinal dos mamíferos, ser fonte de aminoácidos e retinol, transporte de ácidos graxos e auxílio na digestão lipídica (Reddy et al. 1988, Perez et al. 1990).

Outra função referente a esta proteína é a sua importância na transferência de imunidade passiva, juntamente com as imunoglobulinas (Perez et al. 1990), conforme verificado pela alta correlação positiva $(r=0,92 ; \mathrm{P}<0,0001)$ en- tre a proteína total e a $\beta$-lactoglobulina (Quadro 2), como constatado por Rocha (2010). Esta alta correlação está diretamente relacionada aos valores elevados da concentração da $\beta$-lactoglobulina no colostro, sendo neste estudo inferior apenas às imunoglobulinas de classe IgG (Quadro 1), como verificado no trabalho de Levieux et al. (2002), em que constataram o mesmo comportamento no colostro de cabras (IgG de $47,3 \mathrm{mg} / \mathrm{mL}$ e $\beta$-lactoglobulina de $20,7 \mathrm{mg} /$ $\mathrm{mL}$ ). Em decorrência desta função da $\beta$-lactoglobulina, ela está presente nos produtos que utilizam colostro como ingrediente para fornecer imunidade ao recém-nascido (Sutton \& Alston-Mills 2006).

$\boldsymbol{\alpha}$-lactoalbumina. A concentração média desta variável no colostro foi de $1.008,81 \mathrm{mg} / \mathrm{dL}$, estando inferior aos valores verificados por Baroza (2007) e superiores aos relatados por Levieux \& Ollier (1999), Levieux et al. (2002) e Sant'ana (2004) no colostro de vacas e cabras. Na espécie ovina, Perez et al. (1990), trabalhando com colostro, observaram também concentrações inferiores, que decresceu na segunda semana de lactação, chegando a cerca de $70 \%$ do valor inicial. A concentração desta proteína mais elevada no colostro pode ser justificada por sua importância como fonte protéica para o neonato (Rocha et al. 2009). Por ser uma metaloproteína, é fisiologicamente importante na síntese da lactose, facilitando a produção e a secreção do leite. Os cátions divalentes dos ligamentos da $\alpha$-lactoalbumina $\left(\mathrm{Ca}^{2++}, \mathrm{Zn}{ }^{2++}\right)$ facilitam a absorção de minerais essenciais. Durante sua digestão, seus peptídeos com propriedades antibacterianas e imunoestimulatórias, auxiliam na proteção contra infecções, auxiliando na proteção do neonato (Stãnciuc \& Râpeanu 2010).

\section{CONCLUSÃO}

A administração dos suplementos na fase final da gestação das ovelhas não influenciou na concentração das proteínas identificadas no colostro (IgA, IgG, lactoferrina, albumina, $\beta$-lactoglobulina, $\alpha$-lactoalbumina e $\beta$-caseína). Em decorrência da escassez de trabalhos relacionados ao tema, os dados coletados, por meio deste protocolo, podem servir como referência para futuros estudos na espécie ovina.

Agradecimentos.- À Fundação de Amparo à Ciência e Tecnologia do Estado de Pernambuco (FACEPE) pelo auxílio financeiro.

\section{REFERÊNCIAS}

Akins M.S., Bertics S.J., Socha M.T. \& Shaver R.D. 2013. Effects of cobalt supplementation and vitamin $\mathrm{B}_{12}$ injections on lactation performance and metabolism of Holstain dairy cows. J. Dairy Sci. 96(3):1755-1768.

Afonso J.A.B. 2006. Toxemia da prenhez. Veterinária e Zootecnia, CRMVPE, 26:7.

Baroza P.F.J. 2007. Proteínas, enzimas e minerais na secreção lacteal de cabras e vacas, nos primeiros 30 dias pós-parto, congelada ou não. Dissertação de Mestrado em Clínica Veterinária, Faculdade de Ciências Agrárias e Veterinária, Universidade Estadual Paulista, Jaboticabal, SP. 113p.

Boland T.M., Hayes L., Sweeney T., Callan J.J., Baird A.W., Keely S. \& Crosby T.F. 2008. The effects of cobalt and iodine supplementation of the pregnant ewe diet on immunoglobulin $\mathrm{G}$, vitamin $\mathrm{E}, \mathrm{T}_{3}$ and $\mathrm{T}_{4}$ levels in the progeny. Animal 2(2):197-206.

Bolzan G.N., Antunes M.M., Schwegler E., Pereira R.A. \& Corrêa M.N. 2010. 6f. Importância da transferência da imunidade passiva para a sobrevivência de bezerros neonatos. Núcleo de Pesquisa, Ensino e Extensão em 
Pecuária, Universidade Federal de Pelotas. Disponível em <http://www2. ufpel.edu.br/nupeec/> Acesso em 16 dez. 2013.

Borges F.B. 2003. Uso de niacina na alimentação de vacas de alta produção. Disponível em <www.zootec.com.br/niacina.htm> Acesso em 28 abr. 2007.

Brock J.H. 1980. Lactoferrin in human milk: its role in iron absorption and protection against enteric infection in the newborn infant. Archs Dis. Childhood 55:417-421.

Chiofalo V., Todaro M., Liotta L., Margiotta S., Manzo T. \& Leto G. 2005. Effect of propylene glycol on pré- and postpartum performance by dairy ewes. Small Rumin. Res. 58:107-114.

Diffay B.C., McKenzie D., Wolf C. \& Pugh D.G. 2004. Abordagem e exame de ovinos e caprinos, p.1-19. In: Pugh D.G. (Ed.), Clínica de Ovinos e Caprinos. Roca, São Paulo.

Duncan W.R.H., Morrison E.R. \& Garton G.A. 1981. Effects of cobalt deficiency in pregnant and pos-parturient ewes and their lambs. Brit. J. Nutr. 46:337-344.

Eckersall P.D. 2008. Proteins, proteomics, and the dysproteinemias, p.117155. In: Kaneko J.J., Harvey J.W. \& Bruss M.L. (Eds), Clinical Biochemistry of Domestic Animals. 6th ed. Academic Press, New York

Fagliari J.J. \& Silva S.L. 2002. Hemograma e proteinograma plasmático de equinos hígidos acometidos por abdômen agudo, antes e após laparotomia. Arq. Bras. Med. Vet. Zootec. 54(6):559-586.

Hernández-Castellano L.E., Almeida A.M., Castro N. \& Argüello A. 2014. The colostrum proteome, ruminant nutrition and immunity: a review. Curr. Protein Pept. Sci. 15:64-74.

Indyk H.E. \& Filonzi E.L. 2003. Determination of immunoglobulin G in bovine colostrum and milk by Direct Biosensor SPR-Immunoassay. J. AOAC Int. 86(2):386-393.

Kelly G.S. 2003. Bovine colostrums: a review of clinical uses. Altern. Med. Rev. 8:378-394.

Kincaid R.L. \& Socha M.T. 2007. Effect of cobalt supplementation during late gestation and early lactation on Milk and serum measures. J. Dairy Sci. 90(4):1880-1886.

Korhonen H. \& Pihlanto A. 2007. Technological options for the production of health-promoting proteins and peptides derived from milk and colostrum. Curr Pharm Des. 13:829-843.

Laemmli U.K. 1970. Cleavage of structural proteins during the assembly of the head of bacteriophage T4. Nature 227:680-685.

Lahov E. \& Regelson W. 1996. Antibacterial and immunostimulating casein-derived substances from milk: Casecidin, isracidin peptides. Food Chem. Toxicol. 34:131-145.

Larson B.L. \& Kendall K.A. 1957. Protein production in the bovine daily production of the specific milk proteins during the lactation period. J. Dairy Sci. 40(3):377-386.

Lemos V.L., Guaraná E.L.S., Afonso J.A.B., Fagliari J.J., Silva P.C., Soares \& Mendonça C.L. 2013. Proteinograma do soro lácteo de ovelhas da raça Santa Inês em diferentes fases de lactação. Pesq. Vet. Bras. 33:807-812.

Levieux D., Morgan F., Geneix N., Masle I. \& Bouvier F. 2002. Caprine immunoglobulin G, $\beta$-lactoglobulin, $\alpha$-lactalbumin and serum albumin in colostrums and milk during the early post partum period. J. Dairy Res. 69:391-399.

Levieux D. \& Ollier A. 1999. Bovine immunoglobulin G, $\beta$-lactoglobulin, $\alpha$-lactalbumin and serum albumin in colostrum and milk during the early post partum period. J. Dairy Res. 66:421-430.

Little T.M. \& Hill F.J. 1978. Agricultural experimentation: design and analysis. John Wiley and Sons, New York. 350p.

Migliore-Samour D. \& Jollès P. 1988. Casein, a prohormone with an immunomodulating role for the newborn? Experientia 44:188-193.
Moretti D.B., Kindlein L., Pauletti P. \& Machado-Neto R. 2010. IgG absorption by Santa Ines lambs fed Holstein bovine colostrum or Santa Ines ovine colostrums. Animal 4(6):933-937.

Nielsen N.I. \& Ingvartsen K.L. 2004. Propylene glycol for dairy cows: a review of the metabolism of propylene glycol and its effects on physiological parameters, feed intake, milk production and risk of ketosis. Anim. Feed Technol. 115:191-213.

Nowak R. \& Poindron P. 2006. From birth to colostrum: early steps leading to lamb survival. Reprod. Nutr. Develop. 46(4):431-446.

NRC 2007. Nutrient Requirements of Sheep. 7th ed. National Research Council, National Academy Press, Washington, DC. 384p.

Östensson K. 1993. Variations during lactation in total and differential leukocyte counts, $\mathrm{N}$-acetyl- $\beta$-D-glucosaminidase, antitrypsin and serum albumin in foremilk and residual milk from non-infected quarters in the bovine. Acta Vet. Scand. 34(1):83-93.

Perez M.D., Sanchez L., Aranda P., Ena J.M., Oria R. \& Calvo M. 1990. Synthesis and evolution of concentration of $\beta$-lactoglobulin and $\alpha$-lactalbumin from cow and sheep colostrums and milk throughout early lactation. Cell. Mol. Biol. 36(2):205-212.

Reddy M., Kella N.K.D. \& Kinsella J.E. 1988. Structural and conformational basis of the resistance of $\beta$-lactoglobulin to peptic and chymotryptic digestion. J. Agric. Food Chem. 36:737-741.

Robblee E.D., Erickson P.S., Whitehouse N.L., McLaughlin A.M., Schwab C.G., Rejman J.J. \& Rompala R.E. 2003. Supplemental lactoferrin improves health and growth of Holstein calves during the preweaning phase. J. Dairy Sci. 86(4):1458-1464.

Rocha T.G., Franciosi C., Nociti R.P., Silva P.C., Sampaio A.A.M. \& Fagliari J.J. 2009. Eletroforetograma das proteínas do soro lácteo de vacas Canchim primíparas e pluríparas. Anais VIII Congresso Brasileiro de Buiatria. Ciênc. Anim. Bras. (Supl.1):220-225.

Rocha T.G. 2010. Avaliação da transferência de imunidade passive em bezerros de vacas da raça Canchin. Dissertação de Mestrado em Clínica Veterinária, Faculdade de Ciências Agrárias e Veterinária, Universidade Estadual Paulista, Jaboticabal, SP. 108p.

Rudovsky A., Locher L., Zeyner A., Sobiraj A. \& Wittek T. 2008. Measurement of immunoglobulin concentration in goat colostrum. Small Rumin. Res. $74: 265-269$

Sant'ana V.A.C. 2004. Proteinograma do leite de vacas: padrões e variabilidade. Tese de Doutorado em Medicina Veterinária, Universidade de São Paulo, SP. 161p.

Santos R.A., Campos A.G.S.S., Afonso J.A.B., Soares P.C. \& Mendonça C.L. 2012. Efeito da administração de propileno glicol e cobalto associado à vitamina B12 sobre o perfil metabólico e a atividade enzimática de ovelhas da raça Santa Inês no periparto. Pesq. Vet. Bras. 32(Supl.1):6066.

Stãnciuc N. \& Râpeanu G. 2010. An overview of bovine $\alpha$-lactalbumin structure and functionality. Food Technol. 34(2):82-93.

SAS 2009. SAS User's Guide: statistics version. Statistical Analyses System Institute, Cary, New York.

Sutton L.F. \& Alston-Mills B. 2006. B-lactoglobulin as a potential modulator of intestinal activity and morphology in neonatal piglets. Anat. Rec. A 288:601-608.

Tizard I.R. 2013. Immunity in the fetus and newborn, p.225-239. In: Ibid. (Ed.), Veterinary Immunology. Elsevier Saunders, St Louis.

Weinberg E.D. 1978. Iron and Infection. Microbiol. Revs 42(1):45-66.

Yekta M.A., Cox E., Goddeeris B.M. \& Vanrompay D. 2011. Reduction of Escherichia coli 0157: H7 excretion in sheep by oral lactoferrin administration. Vet. Microbiol. 150:373-378. 